\title{
DIAGNOSTIC UTILITY OF ADENOSINE DEAMINASE ACTIVITY IN TUBERCULAR PLEURAL EFFUSION
}

Priya Darshini K.S ${ }^{1}$, Reena R², Aliya Nussrath ${ }^{3}$.

1. Associate Professor, Department of Biochemistry, Rajarajeshwari Medical College, Bangalore.

2. III Year Post Graduate, Department of Biochemistry, Rajarajeshwari Medical college, Bangalore.

3. Professor \& HOD, Department of Biochemistry, AIMS, Bellur.

\section{CORRESPONDING AUTHOR:}

Dr. Priyadarshini K.S.

Associate Professor,

Department of Biochemistry,

Kambipura, Mysore Road,

Bangalore- 570074.

E-mail: drpriyabio@gmail.com

\section{HOW TO CITE THIS ARTICLE:}

Priya Darshini K.S. Reena R. Aliya Nussarth. "Diagnostic Utility of Adenosine Deaminase Activity in Tubercular Pleural Effusion." Journal of Evolution of Medical and Dental Sciences 2013; Vol2, Issue 24, June 17; Page: 4358-4362.

ABSTRACT: INTRODUCTION: Tuberculosis is a most common cause of exudative pleural effusion in India which usually occurs as a complication of primary pulmonary tuberculosis. Adenosine deaminase $(\mathrm{ADA})$ is an enzyme which is produced by activated T-lymphocytes in response to the mycobacteria. ADA in pleural fluid will be comparatively higher than in serum indicating the local synthesis of ADA by activated T-lymphocytes. Thus the estimation of ADA in tubercular pleural fluid helps in the diagnosis of tubercular pleural effusion. The purpose of this study is to find out the role of ADA levels in tuberculous pleural effusions. MATERIALS AND METHODS: This study was conducted at a tertiary care hospital. 30 cases of tubercular pleural effusion, admitted in the medical ward during the period of one year were considered. RESULTS: The pleural fluid ADA levels were more than 40U/L in all cases of tuberculous pleural effusion. CONCLUSION: The determination of ADA level is cost effective and simple procedure to be considered for routine investigation of patients with pleural effusion, especially in a country like India where tuberculosis out numbers the other causes of lymphocytic pleural effusion.

KEYWORDS: Mycobacterium Tuberculosis: pleural effusion: Adenosine Deaminase

INTRODUCTION: Tuberculosis is a major health problem in India. Tubercular pleural effusion is sequelae of primary pulmonary tuberculosis. The incidence tubercular pleural effusion has varied markedly from county to country.

Tubercular pleural effusion is thought to be related to rupture of a subpleural caseous focus in the lung into the pleural space. It is believed that delayed hypersensitivity to tuberculous protein in the pleural space, plays an important role in the pathogenesis of tuberculous pleural effusion'1. 
Although tubercular pleural effusion can resolve spontaneously but up to $65 \%$ untreated tubercular pleural effusion can develop active tuberculosis and other complications. So rapid and accurate diagnosis and prompt treatment is necessary for tubercular pleural effusion ${ }^{3}$.

The diagnosis of tuberculous pleural effusion depends upon the demonstration of tubercle bacilli in the sputum, pleural fluid, or pleural biopsy specimens, or the demonstration of granulomas in the pleura. The mycobacterial cultures of the pleural fluid from most patients with tuberculous pleural effusions are negative and the pleural biopsy is an invasive procedure and is also associated with life threatening complications. Thus there is a need for rapid, safe, simple, sensitive and non invasive laboratory test for the diagnosis of tubercular pleural effusion.

The diagnosis can also be established with reasonable certainty in a patient with lymphocytic pleural effusion by demonstrating elevated levels of adenosine deaminase (ADA). The most widely accepted cut-off value for pleural fluid ADA is $40 \mathrm{U} / \mathrm{L}$. Lymphocytic exudates not due to tuberculosis almost always have adenosine deaminase levels below $40 \mathrm{U} / \mathrm{L}^{1}$.

Adenosine deaminase is an enzyme of purine catabolism, it catalysis the conversion of adenosine to inosine. Its biologic activity is detected in T-lymphocytes and its level remains high in disorders where cellular immunity is stimulated and tuberculosis is one such disease. ADA level in tubercular plural effusion is markedly increased compared to non tubercular effusions and higher ADA activity is seen in pleural fluid than in serum indicating a local synthesis of ADA by Tlymphocytes. ${ }^{5}$

Hence this study was undertaken to determine ADA activity in pleural fluid of tubercular pleural effusion cases.

MATERIAL AND METHODS: The study group comprise of 30 cases of male and female tubercular pleural effusion patients in the age group of 22 to 65 years, admitted in the medical ward of a tertiary care Hospital. The cases were confirmed by clinical and X-ray examination.

After informed consent, the site for pleural fluid aspiration was selected either in mid axillary line or posterior axillary line in the $6^{\text {th }}, 7^{\text {th }}$ or $8^{\text {th }}$ intercostals space. Under aseptic precautions skin, subcutaneous tissue, intercostals muscles and parietal pleura were infiltrated with 5 to $10 \mathrm{ml}$ of $2 \%$ lignocaine. A thoracocentesis $18 \mathrm{G}$ needle attached to a 20 or $50 \mathrm{cc}$ syringe was inserted at the proposed site and fluid was aspirated and collected in a sterile bottle.

The pleural fluid was analyzed for protein, sugar, LDH and ADA activity. Estimation of pleural fluid glucose level was done by glucose oxidase method, total protein by Biuret method, LDH by kinetic method in ERBA-CHEM-5 semi automated analyzer. Adenosine deaminase was estimated by Giusti and Galanti colorimetric method. The ammonia which is produced during the reaction was assayed by modified Berthelot reaction.

RESULTS: Among 30 cases 17 cases were males and 13 cases were females. 


\section{ORIGINAL ARTICLE}

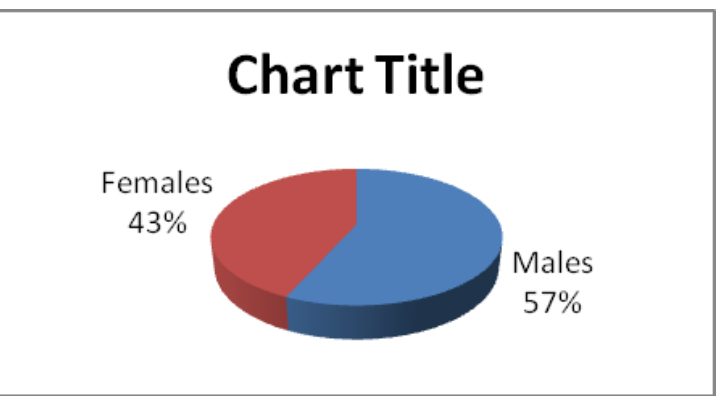

Pie chart: Sex distribution of tubercular pleural effusion cases

\begin{tabular}{|l|l|l|}
\hline & $\begin{array}{l}\text { Pleural fluid Concentration } \\
\text { U/L }\end{array}$ & Mean \pm SD \\
\hline LDH & $220-1316$ & $518.36 \pm 207$ \\
\hline ADA & $50-117$ & $88.53 \pm 17.7$ \\
\hline
\end{tabular}

Table 1: concentration of LDH and ADA in pleural fluid of tubercular pleural effusion cases ADA activity range was 50-170 U/L with mean value $88.53 \mathrm{U} / \mathrm{L}$

\begin{tabular}{|l|l|l|}
\hline & Pleural fluid range & Mean \pm SD \\
\hline Glucose & $50-100 \mathrm{mg} / \mathrm{dl}$ & $67.3 \pm 14.12$ \\
\hline Protein & $3.5-6.4 \mathrm{gms} / \mathrm{dl}$ & $4.63 \pm 0.6$ \\
\hline
\end{tabular}

Table 1: concentration of Glucose and Protein in pleural fluid of tubercular pleural effusion cases

DISCUSSION: 30 cases of tubercular pleural effusion were studied and pleural fluid was analyzed for biochemical parameters like glucose, protein, LDH and ADA activity.

In our study, all cases of tubercular pleural effusion showed higher level of protein $(>3.5 \mathrm{gm} / \mathrm{dl})$ and LDH $(>200 \mathrm{mg} / \mathrm{dl})$. This in accordance to the Light's criteria of classifying transudative and exudative effusions. The range and mean ADA activity in tubercular pleural effusion cases were 50-170 U/L and 88.53 \pm 17.7 respectively and in all the cases ADA was more than $40 \mathrm{U} / \mathrm{L}$.

D K Gupta, et al., (1990), have concluded that, estimation of ADA in pleural fluid is a useful parameter for the diagnosis of tubercular pleural effusion. According to them, a reference limit of $50 \mathrm{U} / \mathrm{L} .75 \mathrm{U} / \mathrm{L}$ had a specificity of $94.1 \%$ and sensitivity of $100 \%$ in diagnosing tubercular effusion. ${ }^{5}$

In our study the range of ADA activity in tubercular pleural effusion cases was about 50$117 \mathrm{U} / \mathrm{L}$ and mean was $88.53 \pm 17.7$. Hence ADA activity helps to diagnose tubercular pleural effusion. 
Lesley J Burgress., et al (1995), in their study of pleural fluid ADA, showed that, at cut off value of $50 \mathrm{U} / \mathrm{L}$, the sensitivity and specificity was $90 \%$ and $89 \%$ respectively, for the diagnosis of tubercular effusion. ${ }^{6}$

In our present study, using a cut value of $50 \mathrm{U} / \mathrm{L}$, pleural fluid ADA estimation showed sensitivity and specificity of $100 \%$ in differentiating tubercular and non - tubercular pleural effusions.

Tom Petterson et al, (1984), studied the ADA activity both in serum and pleural fluid in patients of pleural effusions of different etiology. They found higher levels of ADA in tubercular pleural effusion and they also found higher ADA activity in pleural fluid than in serum indicating a local synthesis of ADA by T- lymphocytes ${ }^{5}$.

R. P. Sing et al (1986), showed that, pleural fluid ADA activity was significantly higher in tubercular effusion, when compared to malignant and transudative effusions ${ }^{8}$.

Gilhothra R., et al., (1989), compared tubercular pleural fluid ADA with non - tubercular pleural fluid ADA and concluded that, higher values of ADA is strongly suggestive of tubercular etiology. However, in their work, 4 out of 26 cases of malignant effusions showed higher ADA levels, but they concluded that, pleural fluid ADA levels of less than 40 units/L excludes tubercular etiology9.

CONCLUSION: In the present study an attempt has been made to estimate the pleural fluid ADA activity in tubercular pleural effusion.

The mean ADA activity in tubercular effusion was 88.53 \pm 17.7. This indicates that, estimation of ADA is a very good parameter to differentiate tubercular from non tubercular pleural suffusion and thus help for the diagnosis of tubercular pleural effusion.

Most current laboratory tests like pleural tissue culture and histopathology are slow, invasive, comparatively less sensitive and their results depends on the availability of expert opinion. From the present study it is evident that, measurement of ADA in pleural fluid is a rapid, safe simple, sensitive and non invasive laboratory test for the diagnosis of tubercular pleural effusion.

ADA estimation being a simple colorimetric method is imminently suitable for the rapid diagnosis of tubercular effusion in field setting. The easiest way to establish the diagnosis of tuberculous pleuritis in a patient with lymphocytic pleural effusion is to generally demonstrate a pleural fluid ADA activity. A large number of patients are required to confirm our findings further and establish the definitive criteria.

\section{REFERENCES:}

1. Invited Review Series: Tuberculosis Series "Update On Tuberculous Pleural Effusion” R Ichard, W., Respirology (2010) 15, 451-458.

2. World Health Organization. Tuberculosis Fact sheet $N^{\circ} 104$ Reviewed February 2013.

3. Roper WH, Waring JJ. Primary serofibrinous pleural effusion in military personnel. AM Rev Respir Dis. 1995; 71:616-34.

4. A clinicopathological study of tuberculous pleural effusion in a tertiary care hospital Amitabha Basu1, Indranil Chakrabarti2, Nilanjana Ghosh3, Subrata Chakraborty, 2012, 5 : 3:168-172 
5. Tom petterson, Kaasina Ojala and Theodor H. Deber, 1984, "Adenosine deaminase in the diagnosis of pleural effusion", Acta Med. Scand, 215:299-304.

6. Gupta. S.K., Mitra K., 1987," Diagnostic value of adenosine deaminase assay in body fluids”, J. Assoc. Phy. India, 35:173-4.

7. Lesley J. Burgess, Trans J. Maritz, lrene Re Roux, et al., 1995, "Use of adenine deaminase as a diagnostic tool for tuberculous pleurisy" Thorax, 50: 672-674

8. Singh R.P., Narayan R.K., Katiyar S.K, et al., 1986, "Adenosine deaminase activity in pleural effusion", JAPI, 34960:427.

9. Gilhothra R, Schgal S and jindal S.K., 1989, "Pleural biopsy and adenosine deaminase anzyme activity in effusions of different etiology", Lung India, VII (3): 122 - 124.

10. Piras M.A., and Gakis C., 1978, "Adenosine deaminase activity in pleural effusion. An aid to differential diagnosis" BMJ, 2: 1751- 1752.

11. Sharma S.K. and Mohan A (Ed), 1996, "Adenosine deaminase in the diagnosis of tubercular pleural effusion”, India J. Chest Dis Allied Sci, 38:69-71.

12. Haro M, Reiz - manzano J, Morera J, et al., 1997, " Analysis of 90 cases of pleural tuberculosis in relation to adenosine deaminase levels”, Med. Clin Barc, 108 (12): 452 - 4.

13. Inma Ocana, jose M. Martinez - Vazquez, Rosa M. Segura, et. 1983, "Adenosine deaminase in pleural effusions", Chest, 84(1): 51 -53.

14. Jhamaria J.P., Jenaw R.K., Luhada S.K., et al., 1998," Serum adenosine deaminase in differential diagnosis of pulmonary tuberculosis and common non - tubular respiratory diseases", Ind. J. Tab, 35;25 - 27.

15. Martin B. Vander and William N. Kelleyg, 1976, "Human adenosine deaminase distribution and properties," The journal of Biological chemistry, 251 (18): 5448 - 5456.

16. S.K. Verma. A.L. Dubey, S.L. Tewerson, Davashish Sharma.2008. "Adenosine Deaminase (ADA) Level in Tubercular Pleural Effusion”. Lung India. Jul-Sep; 25(3): 109-110. 